NBER WORKING PAPER SERIES

\title{
THE INTRODUCTION OF TASERS AND POLICE USE OF FORCE: EVIDENCE FROM THE CHICAGO POLICE DEPARTMENT
}

\author{
Bocar Ba \\ Jeffrey Grogger \\ Working Paper 24202 \\ http://www.nber.org/papers/w24202 \\ NATIONAL BUREAU OF ECONOMIC RESEARCH \\ 1050 Massachusetts Avenue \\ Cambridge, MA 02138 \\ January 2018
}

We thank Scott Ashworth, John MacDonald, Emily Owens, Daniel Tannenbaum, and participants at the 2017 Transatlantic Workshop on the Economics of Crime for helpful comments. We thank the staff at the Invisible Institute for access to and help with the data. Any errors are our own. Any errors are our own. The views expressed herein are those of the authors and do not necessarily reflect the views of the National Bureau of Economic Research.

NBER working papers are circulated for discussion and comment purposes. They have not been peer-reviewed or been subject to the review by the NBER Board of Directors that accompanies official NBER publications.

(C) 2018 by Bocar Ba and Jeffrey Grogger. All rights reserved. Short sections of text, not to exceed two paragraphs, may be quoted without explicit permission provided that full credit, including $(\odot$ notice, is given to the source. 
The Introduction of Tasers and Police Use of Force: Evidence from the Chicago Police Department Bocar Ba and Jeffrey Grogger

NBER Working Paper No. 24202

January 2018

JEL No. K4

\title{
ABSTRACT
}

In March 2010, the Chicago Police Department changed its Taser policy, issuing the weapons to patrol officers instead of largely restricting their use to sergeants. We used that policy change to obtain difference-in-difference estimates of how the availability of Tasers affected the types of force employed by police, the total number of use-of-force incidents, injury rates per incident, the total number of injuries, and the race distribution of civilians involved in use-of-force incidents. The policy change initially led to a large increase in the use of Tasers, with limited substitution from other types of force. After a period of re-training, substitution between Tasers and other types of force, both greater and lesser, increased. Police injuries fell, but neither injury rates nor the number of injuries to civilians were affected. There is no evidence that Tasers led to a reduction in police use of firearms.

\author{
Bocar Ba \\ Harris School of Public Policy \\ University of Chicago \\ Chicago, IL 60637 \\ bocarba@uchicago.edu \\ Jeffrey Grogger \\ Irving B. Harris Professor of Urban Policy \\ Harris School of Public Policy \\ University of Chicago \\ 1155 E. 60th Street \\ Chicago, IL 60637 \\ and NBER \\ jgrogger@uchicago.edu
}




\section{Introduction}

A key role of the police is to protect people and property. This often requires the use of force, since many would-be arrestees would rather take their chances with patrol officers than submit voluntarily to being arrested. Roughly 20 percent of arrests entail some use of force on the part of police (Eith and Durose 2011).

At the same time, police use of force is controversial. One dimension of controversy involves the frequency of police use of force, with complaints that police use force even when conflicts could be resolved by other means. Another involves the level of force, with claims that the type of force deployed by police is disproportionate to the level of resistance offered by suspects.

Either way, excess force can undermine the legitimacy of the police (Tyler 2004; Ramsey and Robinson 2015; Lum and Nagin 2017; Nagin and Manski 2017). It can also violate civil rights. In the US, courts have held that excess use of force violates the U.S. Constitution's protections against undue search and seizure (ACLU n.d.; Neuscheler and Freidlin 2015). Controversy over police use of force has led to public unrest, including recent cases of mass demonstrations in locales such as Baltimore, Chicago, and Ferguson, Missouri.

To alleviate the controversy, many police departments have adopted weapons involving less-than-lethal force. One example is pepper spray, which was widely deployed by US police agencies during the 1980s and 1990s (Smith et al 2010). A more recent example is the Taser, a conductive energy device (CED) that shoots wired barbs at its target, incapacitating him or her by means of an electrical charge. The idea behind such weapons is to provide patrol officers with a means of subduing resistant subjects that reduces the risk of injury or death relative to other means of force. 
Indeed, injury risk has been the focus of most previous work on CED's. Most studies involve a cross-sectional design, comparing incidents in which Tasers were used to those in which they were not, although a few studies have employed a before-and-after approach. The evidence is somewhat mixed, although most studies have found that CED's reduce the likelihood of injury, particularly to police, in the typical use-of-force incident (Seattle Police Department 2003; Jenkinson et al 2006; Smith et al 2007; MacDonald et al 2009; Taylor et al 2009; Lin and Jones 2010; Smith et al 2010; Taylor et al 2010; Kaminski et al 2015).

In this paper we study injury risk, but we also analyze a range of important outcomes that have received less attention in the literature. We start by analyzing substitution between Tasers and other types of force. Subject to some data limitations, this lets us determine whether Tasers substitute for greater or lesser types of force. This includes firearms, which pose a particularly high risk for innocent bystanders as well as the target subject. The issue of substitution between Tasers and firearms is also important because it has rarely been tested, even as several large police departments have recently established or expanded their Taser arsenals on the grounds that they reduce police shootings (Bustamante 2017, Hinkel 2017, Ho 2017).

We also ask how the availability of Tasers affects the total number of use-of-force incidents. If police become overly reliant on the devices, a phenomenon referred to by Alpert and Dunham (2010) as "lazy cop syndrome," then the availability of Tasers could lead to an increase in use of force. Relatedly, we ask how Tasers affect the total number of injuries to police and civilians. If the availability of Tasers increases police use of force, then injuries could potentially rise, even if injury rates fall.

Finally, we estimate whether the introduction of Tasers changed the race distribution of civilians against whom force is used. Use-of-force incidents involve minority suspects in 
disproportion to their representation in the population (Fryer 2016). Our analysis asks whether the introduction of Tasers reinforces or alleviates that disproportion.

Our approach makes use of a sizeable expansion of the deployment of Tasers undertaken by the Chicago Police Department (CPD). Prior to March 2010, Tasers were issued only to sergeants and field training officers. Starting in that month, CPD changed its policy, issuing roughly 400 Tasers to patrol officers. Its goal was to deploy one weapon per patrol car (Sweeney 2010).

We analyze how the availability of Tasers affects police use of force by way of a differencein-difference analysis. Our comparison group consists of sergeants and field training officers, hereafter referred to as "sergeants," to whom Tasers were available during our entire sample period. Our treatment group consists of patrol officers, to whom Tasers first became widely available after the March 2010 policy change. We compare before-and-after changes in the use of force between patrol officers and sergeants in order to estimate how the availability of Tasers affected patrol officers' use of force.

Figure 1 helps motivate the analysis. There we plot use-of-force incidents involving Tasers for the period 2005-2015. We highlight three key features of the Figure here, postponing a detailed discussion of sources and definitions to Section III below. First, the use of Tasers rose sharply beginning in March 2010. Second, Taser use fell almost as sharply in late 2012. Finally, Taser use then stabilized at a rate roughly double that observed before March 2010.

The remainder of the paper proceeds as follows. The next section provides background information. We provide more discussion of Tasers; weapons policy at CPD; prior work on the effect of intermediate-force weapons; and sketch a theoretical model that helps explain our findings. Section III discusses the data and Section IV discusses our difference-in-difference approach in more detail. Section V presents results, followed by our conclusions in Section VI. 


\section{Background}

\section{A. What is a Taser and what does it do?}

The Taser is a conducted energy device (CED) manufactured by Axon, formerly known as Taser International. Tasers are in widespread use, deployed by 15,000 police agencies (National Institute of Justice 2011). They have been discharged over 2 million times (LAAW International 2017).

When used in "probe mode," the hand-held weapon fires two probes, or darts, that are attached to the handset by means of thin wires that can be up to 30 feet long. It produces 50,000 volts of electricity at 0.004 amps, stunning and temporarily disabling its target by causing involuntary muscular contractions (Jenkinson et al 2006; National Institute of Justice 2011). It can also be used in "drive-stun" mode as a pain-compliance device, whereby the police officer presses the handset directly against the target and discharges a current.

Despite the apparent dangers, most individuals who are shot with Tasers experience no or only minor injuries (Bozeman et al 2009). At the same time, they cause involuntary muscular contractions, which can cause the subject to fall, leading to injuries (National Institute of Justice 20008a). More than 200 people have died after being shocked by a Taser (National Institute of Justice 20008a, 2011). The shock is said to be excruciating painful (Braidwood Commission 2009; Alpert and Dunham 2010). Tasers have been controversial both because of the pain they inflict and because of the risks they pose.

\section{B. CPD Taser policy}

CPD first acquired Tasers in 2004. Initially they were issued only to sergeants and field training officers. Then as now, Taser use was governed by the CPD use-of-force model, which spells out the types of force that police officers are authorized to use in response to different levels 
of resistance offered by subjects. Since our data source is also linked to the CPD use-of-force model, we describe it here in some detail.

Table 1 shows subject resistance levels, police force options, our classification of those options, and reporting requirements. The first column shows that subjects are classified broadly as compliers, passive resisters, active resisters, or assailants. Types of force that are an option in response to a particular resistance level are also options against higher levels of resistance. In general, higher levels of force are authorized for higher levels of resistance. Tasers are an option for use against active resisters and assailants, but not against compliers or passive resisters (Chicago Police Department 2016).

In March 2010 CPD more than doubled the number of Tasers in their inventory, issuing them to patrol officers for the first time with the goal of equipping all squad cars with the weapon (Hinkel 2010). This policy change, or treatment, provides the key explanatory variable for our analysis below. Officers must be certified in order to use Tasers; Figure 1 shows that certifications spiked in March 2010. Use-of-force incidents involving Tasers rose sharply as well.

In late 2012, use-of-force incidents involving Tasers fell rather abruptly. Shortly prior to that time, CPD purchased a new model of Taser and required officers to become certified in its use (Hinkel 2017). Figure 1 shows a sharp increase in new certifications at that time. Between the 2010 and 2012 spikes in certification, Axon changed its Taser training materials. Materials introduced in May 2010 included health and safety issues that were not present in earlier materials, including discussions of cardiac, pulmonary, other physiological and metabolic risks involved with the use of Tasers, as well as higher-risk populations (Taser International 2010). Materials introduced in July 2011 added information on legal matters, including $4^{\text {th }}$ Amendment issues and 
issues involving officers' personal legal liability for excessive use of force (Taser International 2011).

The new weapons and 2012 recertification involved all officers, both sergeants and patrol officers. As such, they do not constitute an intervention whose effects we can evaluate with our difference-in-difference approach. Nevertheless, since we thought they might change the treatment effect associated with the March 2010 introduction of Tasers to patrol officers, we allow our estimated treatment effects to vary before and after September 2012.

\section{Theoretical framework}

To see how the availability of a Taser might affect a police officer's behavior, consider a situation in which the officer seeks to arrest a subject. For simplicity, suppose the officer can use either no force, relying solely on verbal persuasion; a low level of force, such as physical coercion; or a high level of force, such as a firearm. Each option varies in its expected costs to the officer. The costs involve the time involved in resolving the incident; the probability and expected extent of injury to the officer; the probability and expected extent of injury to the subject, which the officer may at least partially internalize; and the probability and expected extent of administrative sanction. Under certain conditions, the police officer will choose her option on the basis of the level of resistance she perceives from the subject: for sufficiently low resistance, she will use no force; for somewhat greater resistance, she will use the low-force option; and for a high level of resistance, she will use the high level of force.

Now add an intermediate force option between the high and low levels, such as a CED. The important observation is that the new option may have lower costs than both the low-and high-force alternatives. Relative to the high-force option, the CED may have less-dire potential consequences for the suspect. The CED may also entail a lower likelihood of being labelled as an excessive use of 
force, and thus less likelihood of provoking an administrative sanction. Under these conditions, the officer would prefer the CED to the firearm, provided the suspect's resistance is not too high. This is how an intermediate-force option could reduce police use of firearms, often among the goals of adopting such weapons.

CED's may also entail less risk of physical injury to the officer than the low-force option, as discussed in Section IV below. At intermediate levels of suspect resistance, the officer may choose the CED over physical coercion. If so, the availability of CED's may cause the officer to substitute away from both the low- and high-force options.

Beyond substitution, the availability of CED's could lead to an increase in the overall use of force. This may happen if the cost of using CED's is lower than that of using no force. For example, a CED may speed the resolution of an incident relative to verbal persuasion, which can be time-consuming. The notion that police could see CED's as an easy way to resolve even low-level incidents has been referred to as "lazy cop syndrome" and has led to concerns about police overuse of the weapon (National Institute of Justice 2011).

\section{Prior research}

The question of weapon substitution has received relatively little attention. Sousa et al (2010) conducted a field-training experiment with 32 police officers each in the treatment and control groups. The control group was equipped with their usual set of weapons; to that the treatment group added Tasers. In response to low to moderate subject resistance, none of the officers deployed their firearms. In response to potentially lethal resistance, 17 members of the control group and 7 members of the treatment group deployed their firearms. Although the difference was statistically significant, the small samples and training-ground setting raise questions as to whether their results would generalize. Lin and Jones (2010) track weapon use among the 
Washington State Patrol from 2005 to 2007, corresponding to one year before and one year after the introduction of Tasers. Over the entire three-year period, they registered only 13 uses of firearms, which provide an insufficient basis for inference. Finally, Taylor et al (2009) compared changes in firearm use among a set of law enforcement jurisdictions that adopted CEDs during their sample period with a set that did not. They found no significant effect of CED adoption on firearm use, although their sample seems to have included only about 100 incidents involving firearms. ${ }^{1}$

Most of the research on the effects of CED's has focused on the link between those weapons and injury risk to police and suspects. The studies differ in their details; some analyze the availability of CED's whereas other focus on their actual use. One feature common to the great majority of studies on injury risk is their use of individual use-of-force incidents as the unit of observation. A typical study relates the occurrence of an injury to characteristics of the incident as well as an indicator for whether a CED was used (Jenkinson et al 2006; Smith et al 2007; MacDonald et al 2009; Lin and Jones 2010; Smith et al 2010; Taylor and Woods 2010; Terrill and Paoline 2011; Paoline et al 2012; Taylor et al 2012; Kaminski et al 2015). Although there are exceptions, most of these studies credit CED's for reducing injuries per incident among both subjects and police.

A limitation of most prior studies is that they speak to only one mechanism by which the availability of CED's may affect injuries. As discussed in the previous subsection, the availability of CED's could affect the number of use-of-force incidents as well as injury rates per incident. The effect of CED's on the total number of subject or officer injuries involves their effects on both the injury rate per incident, an intensive margin, and the number of use-of-force incidents, an extensive

\footnotetext{
${ }^{1}$ In their regression tables, the largest samples that the authors report include fewer than 10,000 incidents. They indicate that only about 1 percent of incidents involved firearms.
} 
margin. If CED's increase the use of force by a sufficient amount, total injuries could rise despite a reduction in injury rates.

Only two studies provide any evidence on the question of whether the availability of CED's increases police use of force. Both were longitudinal studies that focused primarily on other outcomes. However, both provided before-and-after tabulations on the number of use-of-force incidents. Lin and Jones (2010) reported that the number of use-of-force incidents involving the Washington State Patrol rose from 269 in 2005, the year before Tasers were adopted, to 469 in 2007, the year after. Smith et al (2010) report a sharp increase in the number of use-of-force incidents per month in Orlando, Florida after the police department deployed CED's. They report a decrease in Austin, Texas, although they indicate that there is some ambiguity in their Austin data as to whether they are measuring unique incidents or the number of officers involved in the incidents.

The data from Washington State and Orlando are consistent with the notion that the availability of CED's could lead to an overall increase in use-of-force incidents. At the same time, they do not establish a causal link, and it is important to emphasize that the authors do not construe their results as such. Many factors that could contribute to an increase in use of force besides the introduction of CED's. One example would be an increase in crime; another could be a rise in levels of violence in the conduct of narcotics markets. In Section IV, we detail our method for distinguishing the effects of CED availability from trends in other factors that influence police use of force.

\section{Data}

Our main source of data comes from CPD Tactical Response Reports (TRR). CPD requires police officers to fill out a TRR after use-of-force incidents in a manner that is tied to the CPD use- 
of-force model. As shown in Table 1, a TRR must be filed after use-of-force incidents involving subjects classified as active resisters or assailants. ${ }^{2}$ For subjects classified as cooperative or as passive resisters, police are required to fill out a TRR if the subject is injured or alleges an injury. A TRR must also be filed for "all incidents where a subject obstructs a police officer when the obstructing is a physical act between the subject and the officer" (Chicago Police Department 2016b).

TRR's require a supervisor's approval. The supervisor is then supposed to notify the external oversight agency for incidents involving the use of deadly force, the discharge of a firearm, the discharge of a Taser, the discharge of pepper spray and other chemical weapon, or an allegation of excessive force. In principle, the oversight agency is required to investigate those incidents.

However, because of limited resources, the agency does not investigate them all. Starting in 2009, for example, the oversight agency chose to investigate only those Taser incidents involving serious injury or death, a minor (17 and under) or a senior citizen (65 or older).

We obtained the TRR data by means of Freedom of Information Act requests for the period from 2004 through early 2016. We make use of data from 2005 to 2015 because reporting for 2004 and early 2016 seemed incomplete. The key variables in the dataset include the date of the incident, number of involved officers, injured officers, suspects' race and ethnicity, injured suspects, and the type of force used against the suspect. One limitation of our dataset is that it includes no records for incidents involving juvenile suspects.

2 The exception to this rule involves subjects whose only active resistance involves fleeing and when the member's actions did not extend beyond verbal commands and/or control holds utilized in conjunction with handcuffing and searching techniques which do not result in injury or allegation of injury. 
We classify use-of-force incidents into the six categories shown in Table 1 according to the highest type of force used in the incident, which is a common practice in the literature. Our type-offorce hierarchy comes from the CPD use-of-force model. Table 2 reports the distribution of use-offorce incidents over our sample period. Only 15 percent of incidents involved no or minor force. This probably reflects reporting requirements. No and minor force are the only types of force that are authorized for compliant or passively resistant subjects. As mentioned above, TRR's are not required for such incidents unless the subject is injured. We suspect that many incidents involving minor force or less that do not result in injuries are unreported.

Of the 36,112 use-of-force incidents reported during our sample period, 30,641 involved more than minor use of force. A majority involved the use of intermediate force; Tasers were involved in another 10 percent of the incidents. More than one in six of the incidents resulted in the use of major force. Seven hundred thirty-three of the incidents involved firearms, a much larger number than were available in previous studies.

The third and fourth columns of the Table report injury rates per incident to police and suspects, respectively. These injuries are reported by police; the TRR specifically asks whether the subject was injured by the police officer. The injury rates for incidents involving no and minor force are hard to understand. On the one hand, one might expect incidents involving low levels of force to result in low injury rates. On the other, most incidents involving low levels of force are only required to be reported if they result in injury. The observed injury rates may reflect some combination of reporting requirements and voluntary reporting.

Injury rates for incidents involving intermediate force are roughly similar for police and subjects. In contrast, injury rates for Taser-related incidents are quite different. Whereas 36.9 percent of Taser-involved incidents result in injuries to subjects, only 16.5 percent of such incidents 
result in injuries to police officers. The situation reverses for incidents involving major use of force, with injury rates of 53.6 percent for police and 41 percent for subjects. For incidents involving firearms, 28.5 percent of police, and 58.1 percent of subjects, are injured. We suspect that many of the firearm incidents in which subjects were not injured involved shots that missed their mark.

It's worth highlighting that police injury rates are lower for Tasers than for both intermediate and major uses of force. In the context of the model above, this should provide police with an incentive to substitute toward Tasers from both lesser and greater types of force. Of course, this incentive could be mitigated to the extent that police officers internalize risks facing subjects when selecting among types of force, since injury rates for subjects rise with the level of force.

One limitation of our data is that we have no information about the severity of injuries. Although this information is reported on the TRR, it was withheld from our FOIA request on the grounds that it referred to the subject's medical condition. One question we can speak to indirectly is whether probe punctures from Taser shots are included as injuries. The probes themselves are fairly small and the punctures they produce have generally not been classified as injuries by previous researchers (Kaminski et al 2015). Whether the probe punctures themselves are counted as injuries is important, because doing so leads to the conclusion that Tasers raise subject injury rates (Terrill and Paoline 2011; Kaminski et al 2015). Kaminski et al (2015) is the only study of which we are aware that calculates injury rates with and without probe punctures. They report that the subject injury rate from the use of Tasers is 81 percent when probe punctures are included, but only 32 percent when they are excluded. Table 2 shows a subject injury rate of 36.9 percent for use-offorce incidents involving Tasers, suggesting that probe punctures by themselves are generally not being counted as injuries in our data. 
To calculate our difference-in-difference estimates, we aggregated these incident-level data into monthly time series. We constructed monthly data on the number of use-of-force incidents (by type of force and total); the number of incidents involving at least one injury, to police and subjects separately; and the number of incidents involving at least one black subject or one Hispanic subject. Incidents and injuries are normalized by the number of police officers on the CPD payroll each month, divided by $100,{ }^{3}$ in order to provide commensurable magnitudes for patrol officers and sergeants. We use the number of incidents and the number of injuries per 100 police to study the extensive margin: how the introduction of Tasers affected the number of use-of-force incidents and use-of-force-related injuries.

To study injury risk, we analyze monthly injury rates constructed as the number of incidents involving at least one injury divided by the number of incidents. Such injury rates have been the focus of most previous research on the effects of CED's. We use these variables to study the intensive margin: how the introduction of Tasers affected the probability of injury to police and subjects.

Finally, we construct two variables reflecting the race of subjects. The first is the number of incidents in which at least one subject was black divided by the number of incidents. The second is a comparable measure for Hispanics. We use these variables to analyze whether the introduction of Tasers changed the race distribution of subjects involved in use-of-force incidents.

Table 3 presents means of our dependent variables by time period and treatment group. We divide the sample period into the pre-intervention period, from January 2005 to February 2010; the first post-intervention period, from March 2010 to September 2012; and the second postintervention period, following the change of Taser models and the re-training in late 2012, from

${ }^{3}$ CPD payroll data came from a separate FOIA request. 
September 2012 to December 2015. Our treatment observations are based on incidents that involved only patrol officers; our comparison observations are based on incidents that involved sergeants.

The top panel of the Table presents statistics for patrol officers. There we see that the number of incidents involving no force, minor force, or firearms was roughly constant over time. Intermediate-force incidents fell steadily. Taser-related incidents follow the pattern suggested by Figure 1, rising dramatically between the pre-period and first post-period before falling substantially during the second post-period. Incidents involving major force first rose and then fell, as did the total number of use-of-force incidents.

The monthly number of officer injuries per 100 officers fell steadily over the sample period. In contrast, the monthly number of subject injuries per 100 officers rose between the pre-period and the first post-period, then fell during the second post-period to a level slightly below where it started. Officer injury rates/incident fell sharply between the pre-period and the first post-period, then remained flat. Subject injury rates/incident were essentially constant. The shares of incidents involving black and Hispanic subjects likewise were roughly constant over the sample period.

The bottom panel of the Table presents statistics for sergeants. The monthly number of incidents per 100 sergeants involving either no, minor, intermediate, or major force rose between all three periods. In contrast, the number of incidents involving Tasers remained roughly constant during the pre-treatment and first post-treatment periods, then fell markedly after the re-training that occurred in late 2012. The use of firearms fluctuated little over the entire sample period.

\section{Identification and Estimation}

\section{A. Identification}


From the monthly data described above, we seek to estimate the average effect of treatment on the treatment group, that is, the average effect of making Tasers available to patrol officers. To analyze identification via our difference-in-difference estimator, we adopt potential outcomes notation that is adapted for our setting. Denote the treatment dummy by $D_{t}=1$ if Tasers are available at time $\mathrm{t}$ and $D_{t}=0$ otherwise, where time $\mathrm{t}=1, \ldots, \mathrm{T}$ is measured in months, with $\mathrm{t}=1$ denoting January 2005 and $\mathrm{t}=\mathrm{T}$ denoting December 2015. Denote the treatment status indicator by $\mathrm{D}=1$ for the treatment group, i.e., patrol officers, and $\mathrm{D}=0$ for the comparison group, i.e., sergeants. For each month, we have one observation for each value of $\mathrm{D}$, that is, one for the treatment group and one for the comparison group.

Let the potential outcome at time $t$, such as use-of-force incidents per 100 officers, be given by $Y_{t}\left(D_{t}\right)$. Thus $Y_{t}(1)$ is the potential treated outcome, when Tasers are available, and $Y_{t}(0)$ is the potential untreated outcome, when they are not. Let t' denote March 2010, so $t \geq t$ ' denotes the posttreatment period and $t<t$ ' denotes the pre-treatment period. The average effect of treatment on the treated (ATT) at some date $\mathrm{a}>\mathrm{t}^{\prime}$ ' is given by $\operatorname{ATT}_{a}=E\left[Y_{a}(1) \mid D=1\right]-E\left[Y_{a}(0) \mid D=1\right]$.

This is the difference between the expected treated potential outcome and the expected untreated potential outcome among patrol officers, at some post-treatment period $a$. It should be thought of as an intent-to-treat effect, since if measures the effect of the policy of making Tasers available to patrol officers, not the effect of actually using them.

The problem for estimation is that $E\left[Y_{a}(0) \mid D=1\right]$, the expectation of the untreated outcome among patrol officers after Tasers were made available, cannot be estimated from the data. It is a missing counterfactual. However, if we can invoke a parallel trends assumption, we can nevertheless identify the ATT via a difference-in-difference estimator. 
To derive the parallel trends condition, let period $\mathrm{t}=\mathrm{b}$ denote some pre-treatment date. The population analogue of the difference-in-difference estimator can be written as

$\Delta_{a}=E\left[Y_{a}(1) \mid D=1\right]-E\left[Y_{b}(0) \mid D=1\right]-\left\{E\left[Y_{a}(1) \mid D=0\right]-E\left[Y_{b}(1) \mid D=0\right]\right\}$.

The difference-in-difference estimator subtracts the before-after difference in the comparison group, $E\left[Y_{a}(1) \mid D=0\right]-E\left[Y_{b}(1) \mid D=0\right]$, from the before-after difference in the treatment group, $E\left[Y_{a}(1) \mid D=1\right]-E\left[Y_{b}(0) \mid D=1\right]$. It uses the comparison group to adjust for changes that would have taken place in the treatment group had Tasers not been issued to patrol officers. The beforeafter difference for the comparison group involves treated outcomes $Y_{a}(1)$ and $Y_{b}(1)$ because sergeants had access to Tasers during our entire sample period.

Adding and subtracting the missing counterfactual $E\left[Y_{a}(0) \mid D=1\right]$ and rearranging terms, we can rewrite the difference-in-difference estimator as $\Delta_{a}=A T T_{a}+\left\{E\left[Y_{a}(0) \mid D=1\right]-E\left[Y_{b}(0) \mid D=1\right]\right\}-\left\{E\left[Y_{a}(1) \mid D=0\right]-E\left[Y_{b}(1) \mid D=0\right]\right\}$. In this expression, the first term in braces represents a counterfactual trend: it represents the trend in outcomes involving patrol officers that would have obtained had patrol officers never been issued Tasers. The second term in braces represents the trend in outcomes involving sergeants, who had access to Tasers the entire time. Our parallel trend assumption involves these two terms: if the counterfactual trend among outcomes involving patrol officers equals the trend in outcomes involving sergeants, then the difference-in-differences estimator identifies the ATT.

A sufficient condition for the parallel trends assumption to hold at all time periods can be written as: $E\left[Y_{t}(0) \mid D=1\right]-E\left[Y_{t}(1) \mid D=0\right]=\lambda$ for all $\mathrm{t}$ 
For $\mathrm{t} \geq \mathrm{t}^{\prime}$, the first term on the left side of the above expression cannot be estimated because it represents a missing counterfactual. However, for $\mathrm{t}<\mathrm{t}$ ', the expressions can be estimated and used to test the validity of the assumption.

\section{B. Estimation}

For estimation, we can define the observed dependent variables, such as use-of-force incidents/100 police, in terms of the potential outcomes, the treatment dummy, and the treatment status dummy as $Y_{D t}=\left(1-D+D D_{t}\right) Y_{t}(1)+D\left(1-D_{t}\right) Y_{t}(0)$, which implies that $Y_{0 t}=Y_{t}(1)$ for $t=1, \ldots T ; Y_{1 t}=Y_{t}(0), t<t^{\prime}$; and $Y_{1 t}=Y_{t}(1), t \geq t^{\prime}$. In the development above, we allowed the ATT to vary by month. For estimation purposes, we impose more structure, allowing the ATT to vary between the first and second post-treatment periods, but assuming it to be constant within those periods. Letting $t^{\prime \prime}$ denote September 2012, we assume $A T T_{t}=\beta_{1}$ for $t=t^{\prime}, \ldots, t^{\prime \prime}-1$, and $A T T_{t}=\beta_{2}$ for $t=t^{\prime \prime}, \ldots, T$. Define two post-treatment dummy variables corresponding to these two time periods: $P_{1 t}=1\left(t^{\prime} \leq t<t^{\prime \prime}\right)$ and $P_{2 t}=1\left(t \geq t^{\prime \prime}\right)$, where the expression $1(z)=1$ if $z$ is true and $=0$ otherwise.

With these definitions, we could use ordinary least squares (OLS) to estimate $\beta_{1}$ and $\beta_{2}$ by means of the following regression:

$$
Y_{D t}=\beta_{0}+\beta_{1} D P_{1 t}+\beta_{2} D P_{2 t}+\beta_{3} P_{1 t}+\beta_{4} P_{2 t}+\beta_{5} D+\varepsilon_{D t} \quad D=0,1 ; t=1, \ldots, \mathrm{T} .
$$

In (1), there are two observations for each time period, one for the patrol officers and one for the sergeants. The ATT's are estimated as the coefficients on interactions between variables defined in terms of treatment status and the post-treatment dummies. In addition, the regression includes the two post-treatment dummies and a treatment status variable $D$, which equals one for the patrol 
officers and equals zero for the sergeants. Finally, $\varepsilon_{D t}$ is an idiosyncratic disturbance term that varies by treatment status and over time.

An equivalent approach to estimating $\beta_{1}$ and $\beta_{2}$ can be obtained by evaluating (1) at $D=0$ and $D=1$, then subtracting the former from the latter. This yields:

$$
Y_{1 t}-Y_{0 t}=\beta_{1} P_{1 t}+\beta_{2} P_{2 t}+\beta_{5}+\varepsilon_{1 t}-\varepsilon_{0 t} \quad t=1, \ldots, \mathrm{T} \text {. }
$$

OLS applied to (2) yields estimates of $\beta_{1}$ and $\beta_{2}$ that are algebraically identical to OLS estimates obtained from (1). The advantage of estimating (2) is that it provides a straightforward means of dealing with potential temporal dependence in the composite disturbance term $\varepsilon_{1 t}-\varepsilon_{0 t}$. To test for dependence, we estimated AR(1) models that allowed for $1^{\text {st }}$-order autocorrelation in $\varepsilon_{1 t}-\varepsilon_{0 t}$. For those few outcomes for which the autocorrelation parameter was significant, we report maximum likelihood estimates. For the remaining outcomes, we report OLS estimates. In all cases, the two sets of coefficients were very similar.

We can augment this specification to test for parallel pre-treatment trends by adding pretreatment period dummies to (2), which is equivalent to adding interactions between those period dummies and the treatment status dummy to (1). Since we have one monthly observation each for patrol officers and sergeants, we aggregate months into years in order to test for parallel trends.

Define the year dummies as

$A_{j t}=1$ if month $t$ falls within year $2000+\mathrm{j}$ and $A_{j t}=0$ otherwise, for $\mathrm{j}=5, \ldots, 9$, and $A_{10 t}=1$ if month $t$ is January or February 2010, and $=0$ otherwise.

Choosing 2009 as the base year, we then generalize equation (2) as

$$
Y_{1 t}-Y_{0 t}=\beta_{1} P_{1 t}+\beta_{2} P_{2 t}+\beta_{5}+\sum_{\substack{j=6 \\ j \neq 9}}^{10} \gamma_{j} A_{j t}+\varepsilon_{1 t}-\varepsilon_{0 t} \quad \quad t=1, \ldots, \mathrm{T}
$$


The test for parallel trends is computed as a test for the joint hypothesis ${ }^{4}$

$$
H_{0}: \gamma_{5}=\cdots=\gamma_{8}=\gamma_{10}=0
$$

\section{Defining the comparison group}

Up to this point, we have discussed the comparison group as consisting of sergeants, or more precisely, of observations constructed from incidents in which sergeants were involved. However, the specific definition of sergeant-involved incidents could have implications for our estimates. The reason has to do with the pre-treatment deployment of Tasers. Before they were assigned to patrol officers, Tasers were available only to sergeants. Thus, sergeants may have been called to incidents specifically to provide Taser support. This is a type of spillover effect and means that Taser use among sergeants may have been higher prior to treatment than it would have been otherwise. Presumably, sergeants' use of Tasers post-treatment would have fallen under this scenario, since there would have been no need to call in a sergeant to provide Taser support once the weapons were available to patrol officers.

To gain insight into this problem and provide a potential solution, we initially worked with two comparison groups. The first we refer to as sergeant-involved. These were constructed from all incidents at which sergeants were present, including those at which patrol officers were present. These would include incidents to which sergeants may have been called expressly to provide Taser support.

We refer to our second comparison group as sergeant-only. It was constructed from all incidents at which only sergeants were present, usually a single sergeant acting on his own. Presumably, these were incidents that the sergeants encountered while on patrol. It should exclude

${ }^{4}$ One might have concerns about the power of this test, considering the number of observations involved. Our concerns are at least partly allayed by the fact that the test often rejects for a nonlinear alternative to the model above, as discussed in Section V.B. 
incidents to which they were called to provide Taser support, since Tasers were available to sergeants from the beginning of our sample period.

Figure 2 plots the number of use-of-force incidents involving Tasers per 100 officers for both of these potential comparison groups. Taser-related incidents were higher pre-treatment, and fell more post-treatment, for the sergeant-involved case than for the sergeant-only case. This is consistent with the spillover hypothesis.

However, what is important for estimation is not so much the effect of spillovers on sergeants' Taser use per se, but rather its effect on their use of other weapons. The reason is that we seek to estimate the effect of CPD's Taser policy on the use of other weapons (and injuries and other outcomes), and it is the before-after change in sergeants' use of those other weapons that affects our difference-in-difference estimates. If Tasers are substitutes for other weapons, then the spillover effect described above may have led sergeants to use other weapons less often pretreatment, and more often post-treatment, than they would have in the absence of the spillover. This would impart a downward bias (in algebraic terms) to our estimates. Depending on the rate at which other weapons substitute for Tasers, it could also impart downward bias on our estimated effect of the introduction of Tasers on the total use of force.

To analyze the importance of spillovers, we estimated all regressions two ways, once with the sergeant-involved comparison group and once with the sergeant-only group. The estimates based on the sergeant-involved group were always algebraically smaller, consistent with the discussion above. For this reason, we present estimates based on the sergeant-only comparison group in the next section.

\section{Results}

\section{A. Main findings}


Table 4 presents estimates of the coefficients of equation (2) above, where the dependent variables measure use-of-force incidents per 100 police, by type of force and for all types of force in total. The coefficient on $P_{1}$ is the estimate of $\beta_{1}$; the coefficient on $P_{2}$ is the estimate of $\beta_{2}$. Standard errors are reported in parentheses. The bottom row of the table presents the p-values for the tests of parallel trends from equation (4). They are based on the regression in equation (3). Except for the case of Tasers themselves, none of the tests rejects the null hypothesis of parallel trends. Figure 3 plots estimates of the $\gamma_{j}$ coefficients from equation (3), together with 90 percent confidence intervals, for total use-of-force incidents. The joint test for parallel trends failed to reject, as seen in at the bottom of column (7). The Figure shows that none of the individual coefficients were significant individually, either.

The estimated treatment effects, reported in the top two rows of Table 4, differ between the two post-treatment time periods. We focus first on the first period, from March 2010 to August 2012, corresponding to $P_{1}$. The estimate in column (4) shows, not surprisingly, that the policy change greatly increased the use of Tasers among patrol officers. This is what Figure 1 would have led one to expect.

More interesting are the estimated effects of introducing Tasers on other uses of force. The effect on incidents in the "no force" category was negative, though small and insignificant. The availability of Tasers reduced the use of minor force by 0.064 , which amounts to about 25 percent of the pre-treatment mean among patrol officers. This coefficient is significant at the 10 percent level. The use of intermediate and major force also fell, although only the coefficient for intermediate force is significant, and then only at the 10 percent level. The coefficient on firearm use is positive, contrary to expectation, though insignificant. Taken as a whole, there is marginally 
significant evidence that the introduction of Tasers led patrol officers to substitute away from lesser types of force, and no significant evidence that they substituted away from greater types of force.

The coefficient in the last column shows that total number of use-of-force incidents rose during the first period following the introduction of Tasers to patrol officers. The estimated increase of 0.277 incidents $/ 100$ officers/month amounts to just over 10 percent of the pre-treatment mean among patrol officers. It is significant at the 10 percent level. Total use-of-force incidents rose because Taser-involved incidents rose by more than enough to counteract the small decline in other types of force.

The second row of the Table reports estimates of $\beta_{2}$, the effect of Tasers during the second post-treatment period, following the re-training of late 2012. The coefficient in column (4), for uses of force involving Tasers, is essentially the same as its counterpart for the initial post-treatment period. This may seem surprising at first, considering the large drop in Taser incidents apparent in Figure 1 that took place in late 2012. The explanation has to do with the behavior of sergeants. Table 2 shows that Taser use fell among sergeants during this period. The estimate of $\beta_{2}$ reflects the fact that the change in Taser use between the second post-treatment period and the pre-treatment period is greater for patrol officers than for sergeants, even though both groups reduced their use of Tasers between the first and second post-treatment periods.

In the period after the re-training of late 2012, the availability of Tasers among patrol officers had different effects on the use of other weapons than it had during the earlier period. Estimates are reported in the second row of the Table. During this period, Tasers widely substituted for other weapons. The estimate in column (3) shows that they substituted for other intermediate uses of force, as one might expect. Column (5) shows that they also substituted for major force. This is consistent with the theoretical model in Section III, considering that Table 2 shows that 
injury rates to police are lower for incidents involving Tasers than for incidents involving major force.

Columns (1) and (2) show that Tasers also substituted for lesser uses of force. Taken at face value, this is consistent with concerns raised by researchers and others regarding over-reliance on Tasers, or "lazy cop syndrome" (Alpert and Dunham 2010). At the same time, CPD reporting requirements are such that it is difficult generalize from reported incidents involving no or low force to the population of such incidents.

Column (6) shows that firearms are the exception to the rule. The estimated effect of Tasers during this time period is negative, but it is barely larger than its standard error. Thus, there is no significant evidence that Tasers substitute for firearms.

Finally, the last column of the Table shows that the availability of Tasers led to a reduction of 0.368 use-of-force incidents/100 officers during the second post-treatment period. This amounts to 14 percent of the pre-treatment average among patrol officers.

Table 5 reports how the introduction of Tasers affected injury rates per incident and the number of injuries per 100 police officers. Results for injuries/use-of-force incident, the focus of most previous research, are reported in column (1) for police officers and column (2) for civilian subjects. The first column shows that the introduction of Tasers reduced the likelihood that officers were injured during an incident involving police use of force. This is true before and after the retraining in late 2012. However, the second column shows that the subjects involved in those incidents enjoyed no such benefit: the coefficients for both time periods are small and insignificant.

Although most studies of Tasers have found that they reduce injury rates, our findings to the contrary have several precedents. Smith et al.'s (2007) analysis of the Richland County, South Carolina Sheriff's Department, for example, showed no link between Taser use and police or 
civilian injuries (see also Smith et al 2010). Likewise, Lin and Jones (2010) found that Tasers reduced police injury rates, but reported mixed results for civilian subjects.

Columns (3) and (4) present results for the number of injuries per 100 police, the product of the number of incidents and the rate of injuries/incident. The estimates in column (3) show that police injuries fell after Tasers were introduced, although the effect was only significant after late 2012. Civilian injuries actually rose slightly, albeit insignificantly, in the first post-treatment period. They fell slightly during the second period, although that coefficient too is insignificant.

The results in Table 6 show how the introduction of Tasers affected the race distribution of civilians involved in police use-of-force incidents. Neither the share of blacks nor Hispanics changed significantly in either follow-up period. Put differently, Tasers did not exacerbate the disproportionate representation of minority civilians involved in use-of-force incidents, but they did not ameliorate it either.

\section{B. Robustness}

The model in equations (1) and (2) assumes additivity of the treatment effect; a natural alternative would be to assume proportionality. If our dependent variables were always positive, this would amount to merely specifying the dependent variable in logs. However, since our dependent variables sometimes equal zero, this option is not available to us. Instead, we estimated negative binomial regression models, which are a variant on the more familiar Poisson model that relaxes the mean-variance equality that is imposed by the Poisson.

For the negative binomial regressions, the dependent variable is specified to be an exponential, rather than linear, function of the treatment status dummy, period dummies, and interactions between the two, as appear on the right side of (1). The dependent variables for these models are the numbers of events, rather than their rate per 100 police or per incident. That is, they 
are the numerators of the dependent variables that appear in the linear regressions reported above. The log of the denominator is included on the right-hand side of the model with a unit coefficient, so that the other coefficients can be interpreted as proportionate changes in the rates. ${ }^{5}$

Estimates from these models were qualitatively similar to those from the linear models reported above. Almost all of the estimated treatment effects had the same signs, and most the estimated treatment effects that were significant at the 5 percent level or better remained significant at similar levels. An important difference involved the tests for parallel trends. Whereas only 1 of the 13 tests of the linear models reported in Tables 4 through 6 rejected the null of parallel trends, 7 of the 13 tests applied to the exponential models rejected. Based on this comparison, we prefer the additive to the proportional specification of the model.

\section{Conclusions}

Tasers and other CED's have long been controversial. Civil libertarians complain that they represent excessive force and are often used when less aggressive tactics would suffice. At the same time, evidence suggests that they reduce injury rates per use-of-force incident. Several large police departments have sought to expand their Taser arsenals on the belief that doing so would reduce police shootings.

We took advantage of a change in policy at the Chicago Police Department to analyze how the availability of Tasers affects police behavior. Prior to the policy change, Tasers had been available only to sergeants and field training officers. Starting in March 2010, they were made available to patrol officers as well. We took advantage of that policy change to study how the availability of Tasers affected patrol officers' choice of tactics in use-of-force incidents, the total

${ }^{5}$ We also estimated an unconstrained version of each model so as to test the null hypothesis that the coefficient on the denominator was equal to one. None of the tests rejected. 
number of use-of-force incidents, injury rates per incidents, and total injuries. We also analyzed how Tasers affected the racial and ethnic makeup of civilians on the other side of those altercations.

Like many other studies, we found that Tasers reduced injury rates among police. Unlike most prior studies, we analyzed whether the availability of Tasers increased the overall use of force among patrol officers. During the first two years it did, although the effect was marginally significant. Total injuries to police fell, but injuries to civilians were unaffected. There is no evidence that Tasers affected police use of firearms.

Roughly two years after the policy change, the department purchased a new model of Taser and re-trained much of the force. After that point, Tasers became a substitute for other types of force, both greater and lesser. Total use of force fell, although subject injuries and police use of firearms remained unaffected.

One lesson is that training appears to matter. The producer of Tasers changed their training materials prior to the 2012 re-training at Chicago PD, adding materials on health risks and officer liability. It would be useful to analyze more systematically how different approaches to training affect police officers' choice of tactics in confrontational situations. 


\section{References}

Alpert, G. P., \& Dunham, R. G. (2010). Policy and Training Recommendations Related to Police Use of CEDs: Overview of Findings from a Comprehensive National Study. Police Quarterly, 13(3), 235-259. https://doi.org/10.1177/1098611110373993

American Civil Liberties Union. (n.d.). Less Lethal Force: Proposed Standards for Massachusetts Law Enforcement Agencies.

Bozeman, W. P., Hauda, W. E., Heck, J. J., Graham, D. D., Martin, B. P., \& Winslow, J. E. (2009). Safety and Injury Profile of Conducted Electrical Weapons Used by Law Enforcement Officers Against Criminal Suspects. Annals of Emergency Medicine, 53(4), 480-489. https://doi.org/10.1016/j.annemergmed.2008.11.021

Braidwood Commission on the Death of Robert Dziekanski. (2010). Why? The Robert Dziekanski Tragedy. Retrieved from http://www2.gov.bc.ca/assets/gov/law-crime-and-justice/about-bcjustice-system/inquiries/braidwoodphase2report.pdf

Bustamante, Alexander A. 2017. "Overview of Less-Lethal Force Tools and Deployment." Los Angeles. http://www.lapdpolicecom.lacity.org/022817/BPC_17-0057.pdf.

Chicago Police Department. (2016). TACTICAL RESPONSE REPORT - FORM PREPARATION INSTRUCTIONS, CPD-63.467, 467.

Chicago Police Department. (2016). TACTICAL RESPONSE REPORT (Vol. CPD-11.377).

Chicago Police Department. (2016b). Incidents Requiring the Completion of a Tactical Response Report (Vol. General Or). Chicago, Illinois. Retrieved from http://directives.chicagopolice.org/directives/data/a7a57be2-1291da66-88512-91e2cdd76fd8ae76d83d.html

Chicago Police Department. (2016a). Force Options. Chicago, Illinois. Retrieved from http://directives.chicagopolice.org/directives/data/a7a57be2-128ff3f0-ae912-90011d970b87782d543f.html

Eith, C., \& Durose, M. (2011). Contact between the Police and Public, 2008. Special Report. Retrieved from https://www.bjs.gov/content/pub/pdf/cpp08.pdf

Fryer, R. G. (2016). An empirical analysis of racial differences in police use of force. Working Paper, (July). https://doi.org/10.3386/w22399

Hinkel, D. (2012, January 1). Doubts surface as police sharply increase Taser use. Chicago Tribune.

Hinkel, D., \& Smith Richards, J. (2017, August 28). Chicago cops get more Tasers, but red flags remain. Chicago Tribune. 
Jenkinson, E., Neeson, C., \& Bleetman, A. (2006). The relative risk of police use-of-force options: Evaluating the potential for deployment of electronic weaponry. Journal of Clinical Forensic Medicine, 13(5), 229-241. https://doi.org/10.1016/j.jcfm.2005.11.006

Kaminski, R. J., Engel, R. S., Rojek, J., Smith, M. R., \& Alpert, G. P. (2015). A Quantum of Force: The Consequences of Counting Routine Conducted Energy Weapon Punctures as Injuries. Justice Quarterly, 32(4), 598-625. https://doi.org/10.1080/07418825.2013.788729

Kaminski, R. J., \& Sorensen, D. W. M. (1995). A multivariate analysis of individual, situational and environmental factors associated with police assault injuries. American Journal of Police, 14(3/4), 3-48. https://doi.org/10.1108/07358549510111938

LAAW International, LLC. (2017). Outline of Partial Selected CEW Research and Information. LAAW International, LLC.

Lin, Y.-S., \& Jones, T. R. (2010). Electronic control devices and use of force outcomes: Incidence and severity of use of force, and frequency of injuries to arrestees and police officers. Policing: An International Journal of Police Strategies \& Management, 33(1), 152-178. https://doi.org/http://dx.doi.org/10.1108/13639511011020647

Lum, C., \& Nagin, D. S. (2017). Reinventing American Policing. Crime and Justice, 46(1), 339393. https://doi.org/10.1086/688462

MacDonald, J. M., Kaminski, R. J., \& Smith, M. R. (2009). The effect of less-lethal weapons on injuries in police use-of-force events. American Journal of Public Health, 99(12), 2268-2274. https://doi.org/10.2105/AJPH.2009.159616

Manski, C. F., \& Nagin, D. S. (2017). Assessing benefits, costs, and disparate racial impacts of confrontational proactive policing. Proceedings of the National Academy of Sciences of the United States of America, 114(35), 9308-9313. https://doi.org/10.1073/pnas.1707215114

National Institute of Justice. (2008). Monitoring Police Use of Conducted Energy Devices. Retrieved from https://www.nij.gov/topics/technology/less-lethal/pages/monitoring-ceduse.aspx

National Institute of Justice. (2011). Police Use of Force, Tasers and Other Less-Lethal Weapons. Washington, DC. Retrieved from http://www.ncjrs.gov/ pdffiles1/nij/grants/231176.pdf

National Institute of Justice. (2008). How Conducted Energy Devices Work. Washington, DC.

Neuscheler, Jena, and Akiva Freidlin. 2015. "Report on Electronic Control Weapons (ECWs) Submitted to the City of Berkeley." https://sanfranciscopolice.org/sites/default/files/Documents/PoliceCommission/2015StanfordStudy_ECW from DPA.pdf. 
Paoline, E. A. I., Terrill, W., \& Ingram, J. R. (2012). Police Use of Force and Officer Injuries: Comparing Conducted Energy Devices (CEDs) to Hands- and Weapon- Based Tactics. Police Quarterly, 15, 115-136. https://doi.org/10.3868/s050-004-015-0003-8

Perez, J., Wong, G., Thayer, K., Bowean, L., \& Coen, J. (2015, November 27). Crowds close stores, march on Mag Mile to protest Laquan McDonald killing. Chicago Tribune.

Ramsey, C. H., \& Robinson, L. O. (2015). Final Report of the President's Task Force on 21 st Century Policing.

Seattle Police Department. (2003). Special Report on the M26 Advanced TASER ( Pt . 1 ). Seattle. Retrieved from http://www.cityofseattle.net/police/Publications/Special/M26Taser.PDF

Smith, M. R., Kaminski, R. J., Rojek, J., Alpert, G. P., \& Mathis, J. (2007). The Impact of Conducted Energy Devices and Other Types of Force and Resistance on Officer and Suspect Injuries. Policing: Int'l J. Police Strat. \& Mgmt, 30, 423-446.

Smith, M., Kaminski, R., Alpert, G., Fridell, L., MacDonald, J., \& Kubu, B. (2010). A MultiMethod Evaluation of Police Use of Force Outcomes: Final Report to the National Institute of Justice. Washington, DC. Retrieved from https://www.ncjrs.gov/pdffiles1/nij/grants/231176.pdf

Sousa, W., Ready, J., \& Ault, M. (2010). The impact of TASERs on police use-of-force decisions: Findings from a randomized field-training experiment. Journal of Experimental Criminology, 6(1), 35-55. https://doi.org/10.1007/s11292-010-9089-1

Stambaugh, H., Beaupre, D., Icove, D. J., Baker, R., Cassaday, W., \& Williams, W. P. (2000). National Institute of Justice Journal.1043. Research in Brief, (August 2000).

Sweeney, A. (2010, December 6). Police expand Taser use on Chicago streets. Chicago Tribune. Retrieved from http://articles.chicagotribune.com/2010-12-06/news/ct-met-police-taser-use20101206_1_tasers-police-misconduct-field-training-officers

Taser International. (2010). User Certification Course TASER X26 Electronic Control Device. Scottsdale, AZ: Taser International.

Taser International. (2011). User Certification Course TASER X26 Electronic Control Device. Scottsdale, AZ: Taser International.

Taylor, B., \& Woods, D. J. (2010). Injuries to Officers and Suspects in Police Use-of-Force Cases: A Quasi-Experimental Evaluation. Police Quarterly, 13(3), 260-289. https://doi.org/10.1177/1098611110373994

Taylor, B., Woods, D., Kubu, B., Koper, C., Tegeler, B., Cheney, J., ... Kappelman, K. (2009). Comparing safety outcomes in police use-of-force cases for law enforcement agencies that 
have deployed Conducted Energy Devices and a matched comparison group that have not : A quasi-experimental evaluation, (September), 100.

Terrill, W., \& Paoline III, E. A. (2012). Conducted energy devices (CEDS) and citizen injuries: The shocking empirical reality. Justice Quarterly, 29(2), 153-182. https://doi.org/10.1080/07418825.2010.549834

Tyler, T. R. (2004). Enhancing Police Legitimacy. The ANNALS of the American Academy of Political and Social Science, 593(1), 84-99. https://doi.org/10.1177/0002716203262627

US Government Accountability Office. (2005). Taser Weapons: Use of Tasers by Selected Law Enforcement Agencies, (May), 31. 
Figure 1

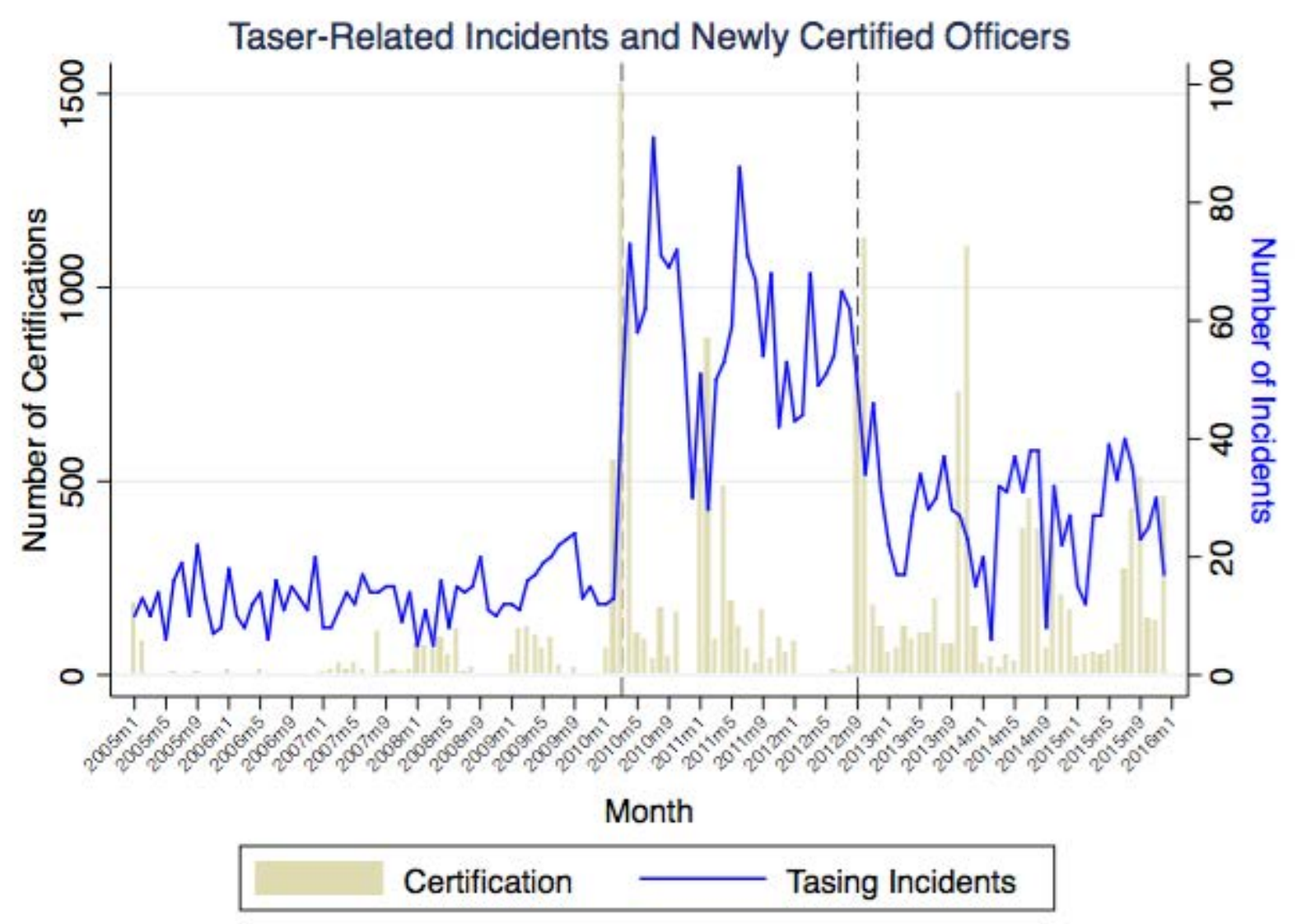


Figure 2

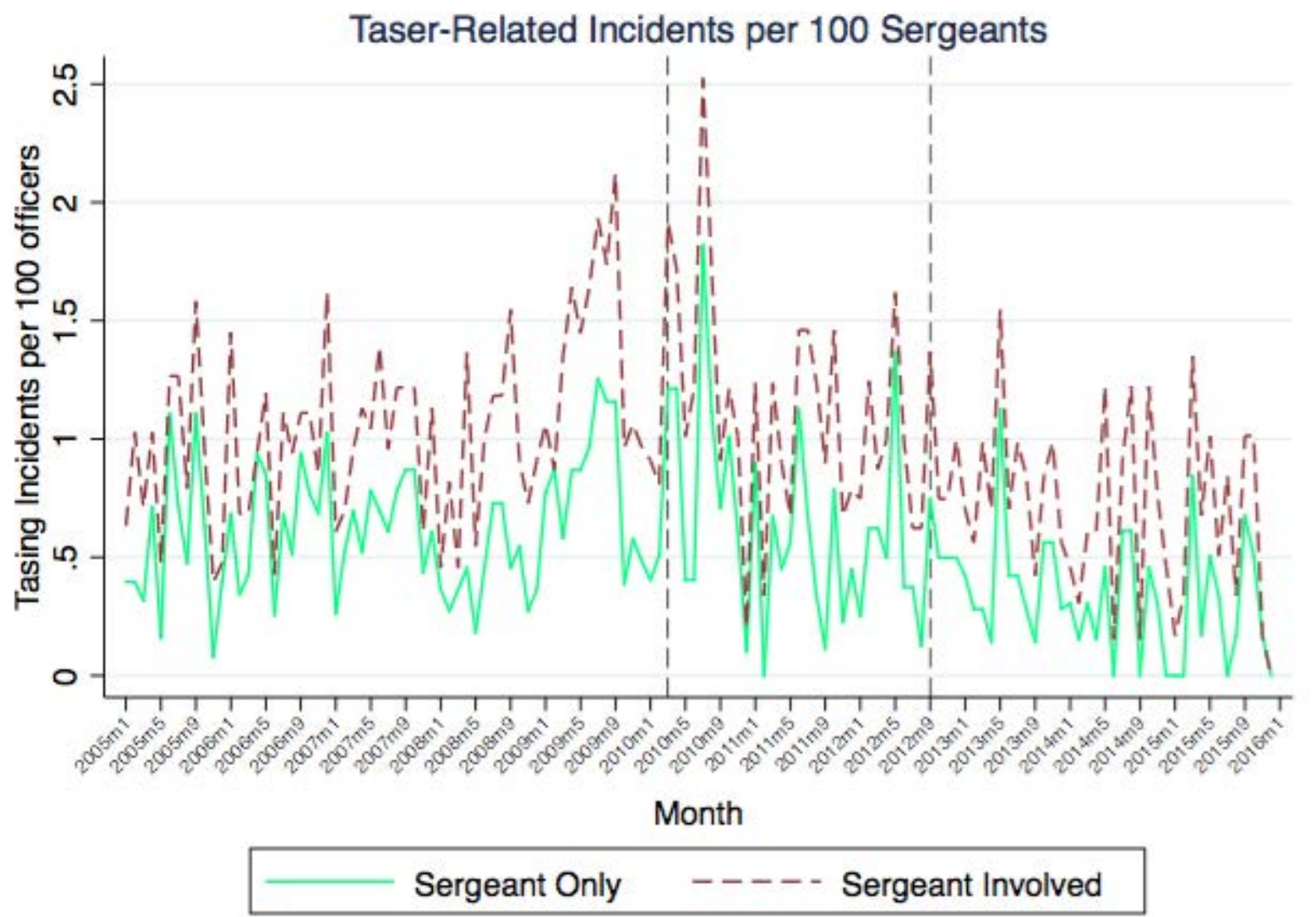


Figure 3

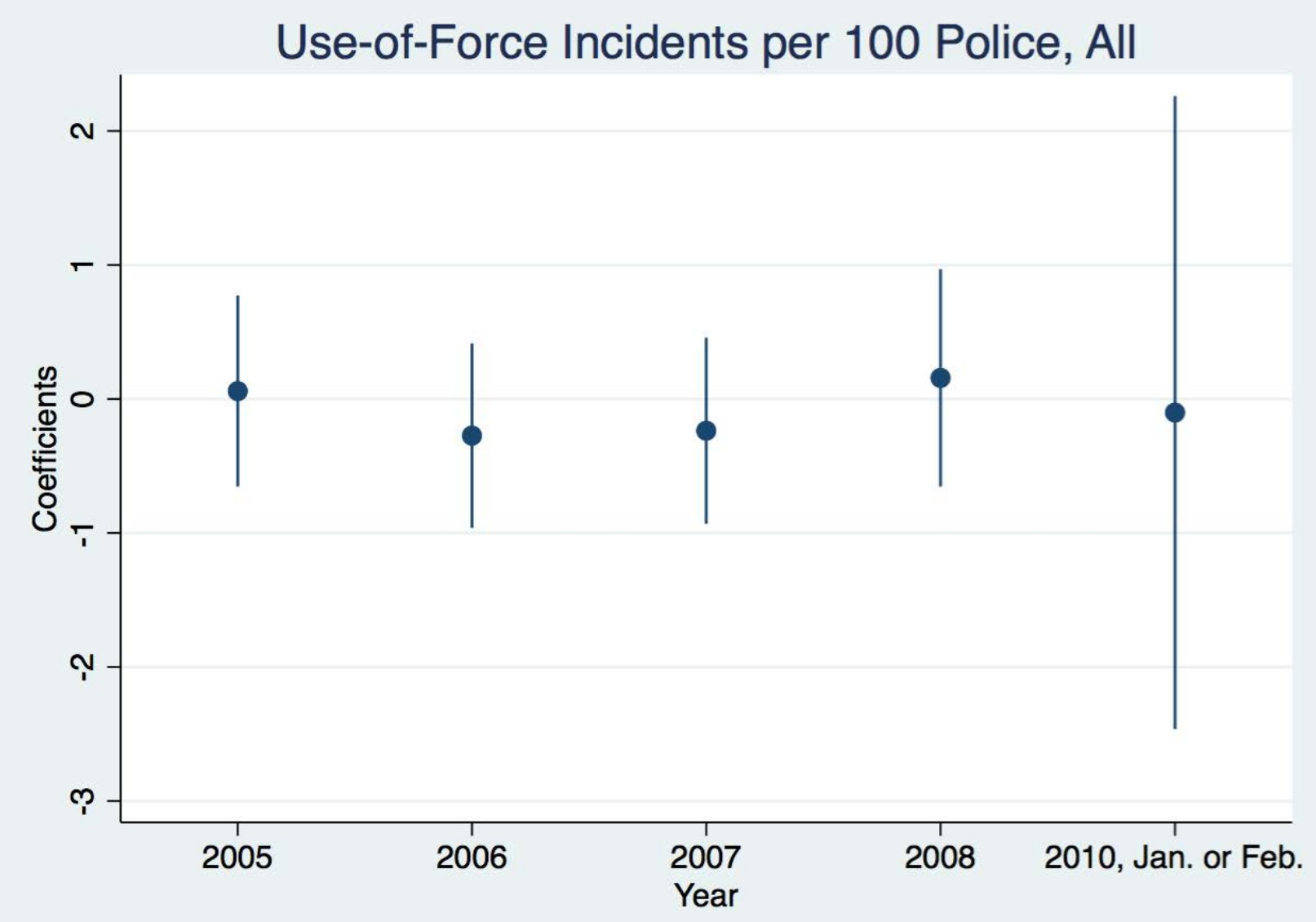


Table 1: Subject resistance, force options, and reporting requirements

\begin{tabular}{|c|c|c|c|}
\hline Subject resistance & Force options & Our classification & TRR required? \\
\hline Cooperative & $\begin{array}{l}\text { Police presence, } \\
\text { Verbal control }\end{array}$ & No force & $\begin{array}{l}\text { If subject injured or alleges } \\
\text { injury }\end{array}$ \\
\hline Passive resistance & $\begin{array}{l}\text { Holding techniques that do not involve } \\
\text { pain-compliance, Pain-compliance } \\
\text { techniques, Control instruments }\end{array}$ & Minor force & $\begin{array}{l}\text { If subject injured or alleges } \\
\text { injury }\end{array}$ \\
\hline Active resistance & $\begin{array}{l}\text { Stunning; OC (pepper) spray, } \\
\text { Capsaicin II powder, LRAD (acoustic } \\
\text { device), Canines, }\end{array}$ & Intermediate force & Yes $^{\mathrm{b}}$ \\
\hline & Taser & Taser & Yes \\
\hline \multicolumn{4}{|l|}{ Assailant } \\
\hline Without weapons & $\begin{array}{l}\text { Striking, Kicking, Powerful locks and } \\
\text { pressure, Impact weapons, Impact } \\
\text { munitions }\end{array}$ & Major force & Yes \\
\hline Likely to cause injury & Same as above & Major force & Yes \\
\hline Likely to cause serious & Chokeholds, & Major force & Yes \\
\hline injury or death & Firearms & Firearms & Yes \\
\hline
\end{tabular}

Notes: First and second columns adapted from Chicago Police Department (2012, 2016a). Third column gives our label for each group of force options. Fourth column adapted from Chicago Police Department (2016b).

a. OC (pepper) spray and LRAD (acoustic device) may also be used under certain circumstances with supervisor approval.

b. A TRR is not required when the subject's only action of resisting is fleeing, and the officer's actions did not extend beyond verbal commands and/or control holds utilized in conjunction with handcuffing and searching techniques which do not result in injury of allegation of injury (Chicago Police Department 2016b). 
Table 2

Distribution of use-of-force incidents and injury rates to police and subjects by type of force

\begin{tabular}{lrrrr}
\hline Type of force & Number & Percent & $\begin{array}{r}\text { Injury } \\
\text { rate/incident, } \\
\text { police (\%) }\end{array}$ & $\begin{array}{r}\text { Injury } \\
\text { rate/incident, } \\
\text { subjects (\%) }\end{array}$ \\
\hline 1. No Force & 2,214 & 6.1 & 19.2 & 9.8 \\
2. Minor Force & 3,257 & 9.0 & 16.8 & 11.9 \\
3. Intermediate Force & 20,128 & 55.7 & 26.0 & 22.3 \\
4. Taser & 3,678 & 10.2 & 16.5 & 36.9 \\
5. Major Force & 6,102 & 16.9 & 53.6 & 41.0 \\
6. Firearm & 733 & 2.0 & 26.5 & 58.1 \\
Total & 36,112 & 100 & 28.5 & 26.0 \\
\hline
\end{tabular}


Table 3

Mean monthly rates of use of force per 100 police, injuries/incident, injuries per 100 police, and share of use-of-force incidents involving minority subjects, by time period and treatment group

\begin{tabular}{|c|c|c|c|}
\hline $\begin{array}{l}\text { A. Patrol officers } \\
\text { Period: } \\
\text { Variable }\end{array}$ & $\begin{array}{l}1 / 2005 \text { to } \\
2 / 2010\end{array}$ & $\begin{array}{l}3 / 2010 \text { to } \\
8 / 2012\end{array}$ & $9 / 2012$ to $12 / 2015$ \\
\hline \multicolumn{4}{|l|}{ Use-of-force incidents/100 police } \\
\hline 1. No Force & 0.17 & 0.20 & 0.17 \\
\hline 2. Minor Force & 0.26 & 0.25 & 0.25 \\
\hline 3. Intermediate Force & 1.65 & 1.56 & 1.48 \\
\hline 4. Taser & 0.02 & 0.55 & 0.26 \\
\hline 5. Major Force & 0.45 & 0.49 & 0.42 \\
\hline 6. Firearm & 0.05 & 0.07 & 0.05 \\
\hline Total & 2.59 & 3.12 & 2.63 \\
\hline Officer injuries/incident & 0.32 & 0.25 & 0.25 \\
\hline Subject injuries/incident & 0.26 & 0.25 & 0.25 \\
\hline Officer injuries/100 police & 0.83 & 0.77 & 0.67 \\
\hline Subject injuries/100 police & 0.68 & 0.78 & 0.65 \\
\hline Share of UOF incidents involving at least one black subject & 0.74 & 0.75 & 0.75 \\
\hline Share of UOF incidents involving at least one Hispanic subject & 0.15 & 0.15 & 0.14 \\
\hline
\end{tabular}


Table 3 (cont.)

\begin{tabular}{|c|c|c|c|}
\hline $\begin{array}{l}\text { B. Sergeants } \\
\text { Period: } \\
\text { Variable }\end{array}$ & $\begin{array}{l}1 / 2005 \text { to } \\
2 / 2010\end{array}$ & $\begin{array}{l}3 / 2010 \text { to } \\
8 / 2012\end{array}$ & $9 / 2012$ to $12 / 2015$ \\
\hline \multicolumn{4}{|l|}{ Use-of-force incidents/100 police } \\
\hline 1. No Force & 0.10 & 0.16 & 0.21 \\
\hline 2. Minor Force & 0.14 & 0.20 & 0.24 \\
\hline 3. Intermediate Force & 0.59 & 0.65 & 0.94 \\
\hline 4. Taser & 0.62 & 0.64 & 0.35 \\
\hline 5. Major Force & 0.14 & 0.20 & 0.24 \\
\hline 6. Firearm & 0.03 & 0.02 & 0.04 \\
\hline Total & 1.62 & 1.87 & 2.03 \\
\hline Officer injuries/incident & 0.18 & 0.17 & 0.16 \\
\hline Subject injuries/incident & 0.24 & 0.23 & 0.21 \\
\hline Officer injuries/100 police & 0.29 & 0.31 & 0.36 \\
\hline Subject injuries/ 100 police & 0.39 & 0.43 & 0.45 \\
\hline Share of UOF incidents involving at least one black subject & 0.69 & 0.72 & 0.69 \\
\hline Share of UOF incidents involving at least one Hispanic subject & 0.16 & 0.15 & 0.16 \\
\hline
\end{tabular}

Notes: UOF=use of force. 
Table 4: Effect of Introducing Tasers on Use of Force Incidents by Type of Force

\begin{tabular}{|c|c|c|c|c|c|c|c|}
\hline \multicolumn{8}{|c|}{ Dependent variable is difference in number of UOF incidents/100 police between patrol officers and sergeants } \\
\hline Variable & $\begin{array}{c}\text { No Force } \\
\text { (1) }\end{array}$ & $\begin{array}{c}\text { Minor } \\
(2)\end{array}$ & $\begin{array}{c}\text { Intermed. } \\
(3)\end{array}$ & $\begin{array}{c}\text { Taser } \\
(4)\end{array}$ & $\begin{array}{c}\text { Major } \\
(5)\end{array}$ & $\begin{array}{c}\text { Firearm } \\
(6)\end{array}$ & $\begin{array}{l}\text { All } \\
(7)\end{array}$ \\
\hline \multirow{2}{*}{$P_{1}$} & -0.025 & -0.064 & -0.143 & 0.518 & -0.023 & 0.021 & 0.277 \\
\hline & $(0.026)$ & $(0.036)$ & $(0.086)$ & $(0.067)$ & $(0.042)$ & $(0.015)$ & $(0.168)$ \\
\hline \multirow{2}{*}{$P_{2}$} & -0.108 & -0.102 & -0.516 & 0.511 & -0.139 & -0.016 & -0.378 \\
\hline & $(0.022)$ & $(0.032)$ & $(0.078)$ & $(0.061)$ & $(0.038)$ & $(0.014)$ & $(0.153)$ \\
\hline \multirow[t]{2}{*}{ Constant } & 0.064 & 0.114 & 1.055 & -0.600 & 0.315 & 0.026 & 0.979 \\
\hline & $(0.018)$ & $(0.020)$ & $(0.049)$ & $(0.038)$ & $(0.024)$ & $(0.009)$ & $(0.122)$ \\
\hline \multirow{2}{*}{$\mathrm{AR}(1)$} & -0.177 & & & & & & 0.173 \\
\hline & $(0.087)$ & & & & & & $(0.077)$ \\
\hline $\mathrm{N}$ & 132 & 132 & 132 & 132 & 132 & 132 & 132 \\
\hline $\begin{array}{l}\text { P-value, test for } \\
\text { parallel trends }\end{array}$ & 0.611 & 0.583 & 0.567 & 0.031 & 0.537 & 0.525 & 0.894 \\
\hline
\end{tabular}

Notes: Standard errors are in parentheses. Coefficients in columns (1) and (7) were estimated by maximum likelihood; those in columns (2)-(6) were estimated by OLS. AR(1) indicates the autoregressive parameter. UOF =use of force. 
Table 5: Effect of Introducing Tasers on Injury Rates/Incident and Injuries

\begin{tabular}{|c|c|c|c|c|}
\hline $\begin{array}{l}\text { Dependent variable is } \\
\text { difference between patrol } \\
\text { officers and sergeants in: }\end{array}$ & Injuri & dent & Injuries/100 & police \\
\hline Variable & $\begin{array}{c}\text { Police } \\
\text { (1) }\end{array}$ & $\begin{array}{c}\text { Subjects } \\
(2)\end{array}$ & $\begin{array}{c}\text { Police } \\
\text { (3) }\end{array}$ & $\begin{array}{c}\text { Subjects } \\
(4)\end{array}$ \\
\hline$P_{1}$ & $\begin{array}{l}-0.065 \\
(0.025)\end{array}$ & $\begin{array}{l}-0.000 \\
(0.025)\end{array}$ & $\begin{array}{l}-0.080 \\
(0.055)\end{array}$ & $\begin{array}{c}0.072 \\
(0.057)\end{array}$ \\
\hline$P_{2}$ & $\begin{array}{l}-0.045 \\
(0.023)\end{array}$ & $\begin{array}{c}0.020 \\
(0.023)\end{array}$ & $\begin{array}{l}-0.225 \\
(0.050)\end{array}$ & $\begin{array}{l}-0.085 \\
(0.052)\end{array}$ \\
\hline $\begin{array}{l}\mathrm{N} \\
\mathrm{P} \text {-value, test for parallel } \\
\text { trends }\end{array}$ & $\begin{array}{c}132 \\
0.626\end{array}$ & $\begin{array}{c}132 \\
0.852\end{array}$ & $\begin{array}{c}132 \\
0.616\end{array}$ & $\begin{array}{c}132 \\
0.907\end{array}$ \\
\hline
\end{tabular}

Notes: Standard errors are in parentheses. 
Table 6: Effect of Introducing Tasers on Race/ethnicity distribution of subjects

Dependent variable is

difference between patrol

officers and sergeants in

share of incidents involving at least one:

Black

\begin{tabular}{lcc} 
Variable & $(1)$ & $(2)$ \\
\hline$P_{1}$ & -0.016 & 0.006 \\
& $(0.029)$ & $(0.022)$ \\
$P_{2}$ & 0.021 & -0.006 \\
& $(0.027)$ & $(0.020)$ \\
\hline $\mathrm{N}$ & 132 & 132 \\
$\mathrm{P}-$-value, test for parallel & 0.504 & 0.750 \\
trends & & \\
\hline
\end{tabular}

Notes: Standard errors are in parentheses. 